\title{
USO DO TERRITÓRIO E CONSOLIDAÇÃO DO AGRONEGÓCIO NA REGIÃO CENTRO- OESTE: UM ESTUDO SOBRE A INTEGRAÇÃO TERRITORIAL ATRAVÉS DO SISTEMA DE TRANSPORTE AÉREO*
}

Fabrício Gallo**

Resumo: Este texto apresenta algumas reflexões sobre o uso de pequenas aeronaves na integração e modernização do território brasileiro. O sistema de transporte aéreo, num país de grande extensão territorial, cumpre papel de destaque no estreitamento dos laços regionais e é um elemento de destaque do circuito espacial produtivo da moderna agricultura desenvolvida no Centro-Oeste brasileiro. Agilizando o transporte dos indivíduos e promovendo os contatos face a face, as pequenas aeronaves de rotas não regulares, em função de sua flexibilidade de deslocamento e de tempo, atuam como vetores fundamentais da integração produtiva do território brasileiro, uma vez que a produção propriamente dita e comando corporativo se dissociaram dadas as possibilidades técnicas do atual período técnico-científico e informacional.

Palavras-chave: paisagem território usado, integração territorial, sistema de transporte aéreo, modernização do território, agronegócio.

\section{USE OF TERRITORY AND CONSOLIDATION OF AGRIBUSINESS IN REGION CENTER-WEST: A STUDY ABOUT THE TERRITORIAL INTEGRATION THROUGH SYSTEM OF AIR TRANSPORT}

\begin{abstract}
The aim of this text is to make some reflections on the use of small aircrafts for the integration and modernization of the Brazilian territory. The system of air transport, in a country of large territorial extension, is very important to narrow the regional ties and it is an important element of the productive space circuit of the modern agriculture developed in the Brazilian CenterWest. The small aircrafts of not-regular routes, act as basic vector of the interactional fluidity, speeding the transport of people, in function of its flexibility of displacement and time, act as basic vector of the productivity integration of the Brazilian territory, a time that the production properly said and corporative command if had separated given to the possibilities techniques of the actual technician-scientific and informational period.
\end{abstract}

Keywords: used territory, territorial integration, system of air transport, territory modernization, agribusiness.

\section{Introdução}

No processo de integração territorial brasileiro, a aviação desempenhou um papel de significativa importância, pois, dada a grande extensão territorial do Brasil, ela possibilitou deslocamentos de maneira rápida e eficiente. À medida que se difundem as modernizações pelo país, mais parcelas do território passam a ser incorporadas dentro da lógica corporativa da economia mundial, cujo objetivo final é a apropriação do lucro máximo. Pode-se afirmar também que o
Estado desempenha um papel de viabilizador deste processo ao implantar próteses geográficas que permitem este uso corporativo do território (rodovias, ferrovias, aeroportos) para atender às necessidades de exportação das grandes empresas.

Ao mesmo tempo em que o país apresenta carências infraestruturais básicas para atender à sociedade nacional como um todo, o que se percebe é um aumento no

\footnotetext{
* Este texto é parte da pesquisa desenvolvida para a dissertação de mestrado $O$ papel do transporte aéreo na integração do território brasileiro, defendida em agosto de 2006, no programa de Pós-graduação em Geografia do Instituto de Geociências da Unicamp, sob orientação do Prof. Dr. Márcio Cataia.

** Doutorando em Geografia pela Universidade de Campinas. E-mail: gallo.fabricio@gmail.com.
} 
número da frota aeronáutica brasileira. Partindo disto pode-se sugerir que quanto mais o país se insere na economia globalizada, onde o uso do território (SANTOS, 2005; 1999) pelas grandes corporações é alavancado, maior é o poder da cidade de São Paulo de concentrar o comando da produção - graças a sua elevada densidade informacional - e é por isso que a aviação executiva tornou-se o meio de transporte mais eficiente para promover 0 contato interpessoal, isto é, o contato face a face entre os empresários e executivos na hora de fechar contratos ou grandes negócios. Assim, um dos objetivos gerais deste texto é tentar apontar como, mesmo com 0 desenvolvimento das novas tecnologias da informação e comunicação, não se pode descartar o contato pessoal no mundo dos negócios, uma vez que este é promovido em grande parte pelo uso da aviação executiva já que o imperativo do período atual é a busca incessante da fluidez.

\section{Gênese do transporte aéreo no Brasil e sua relevância na integração territorial brasileira}

As discussões acerca da integração do território brasileiro são fundamentais para a busca de elementos que ajudem na compreensão da organização territorial no atual período. Buscar um método para se tentar aprofundar tal análise é tarefa que consiste em se levar em conta diversos aspectos da realidade. O partido de método adotado neste texto sugere que não se tome o caminho de interpretação do território nacional a partir dele mesmo, pode-se buscar sua explicação a partir de seu uso interpretando-o como uma concreção do espaço geográfico, que é compreendido por
Santos (2002) como um conjunto indissociável, solidário e contraditório, de sistemas de objetos e sistemas de ações. Para se analisar o território nacional o conceito território usado se apresenta como instrumento analítico de suma relevância, pois, na teoria de Santos (1999, p. 18), "para que o território se torne uma categoria de análise dentro das ciências sociais e com vistas à produção de projetos, isto é, com vista à produção de políticas [...], deve-se tomá-lo como território usado". Silveira (2009, p. 129) lembra que o "território usado abriga as ações passadas, já cristalizadas nos objetos e normas, e as ações presentes, as que se realizam diante de nossos olhos".

Na proposição de Santos (2005, p. 138), "o território são formas, mas território usado são objetos e ações, sinônimo de espaço humano, espaço habitado", assim, um ponto relevante na interpretação geográfica do território é distinguir os agentes da ação (aqueles que detêm o poder para usar o território e atingir os objetivos), pois na análise do território usado há que se considerar sempre a interdependência e inseparabilidade entre a materialidade e seu uso. Como a cada momento histórico diferentes usos são destinados aos objetos técnicos instalados sobre o território, tornase necessário um esforço de periodização.

Santos (1997; 2002) afirma que a história das relações entre sociedade $e$ natureza é a história da substituição de um meio natural, dado a uma determinada sociedade, por um meio cada vez mais instrumentalizado por essa mesma sociedade, ou seja, é a artificialização desse meio através da cristalização, em objetos geográficos, de novas e modernas técnicas desenvolvidas pela humanidade. 
O sistema de transporte aéreo flexível (CATAIA; GALLO, 2007) responde por essa cristalização de objetos técnicos modernos no território, servindo como instrumento privilegiado de integração do território a cada nova etapa modernização. ${ }^{1}$

As políticas de integração territorial impostas pelo Estado brasileiro desde meados do século XIX até as primeiras décadas do século $X X$ se incumbiram, na prática, de manter a integridade territorial do país, ou seja, a preocupação se dava principalmente em não permitir a fragmentação do vasto território, até então pouco povoado em seu interior. Não havia ainda a possibilidade técnica do Estado se fazer presente nos mais distantes pontos do território, inviabilizando com isso os propósitos efetivos de uma integração territorial.

A inexistência de transportes interiores rápidos era responsável por um isolamento quebrado apenas pelos transportes marítimos. Como essas aglomerações [povoamento disperso pelo território] viviam sobretudo do comércio, a hierarquia entre elas dependia das relações com o estrangeiro. Mas não havia uma integração (SANTOS; SILVEIRA, 2001, p. 34).

Estes mesmos autores defendem que a integração nacional do Brasil começa a

\footnotetext{
${ }^{1}$ O sistema de transporte aéreo flexível pode ser entendido como um sistema operado por pequenas aeronaves cujas linhas aéreas não são regulares, isto é, não têm horários e itinerários fixos; operam, inclusive, em pistas não asfaltadas, como se fossem pistas "vicinais"; os horários são totalmente flexíveis, dependendo da demanda; destacam-se as ligações ponto a ponto e a ligação complementar aos voos regulares nacionais e regionais; o sistema de transporte aéreo flexível está presente em todo território nacional, pode servir como ligação entre duas fazendas de um mesmo estado, ou pode servir como ligação entre regiões. Por outro lado, o sistema de transporte aéreo rígido seria aquele das grandes empresas comerciais, com fluxos aéreos regulares e destinos previamente determinados.
}

partir do início do século $X X$ até a década de 1940. No período da circulação mecanizada há o aparelhamento dos portos e a construção de estradas de ferro; surgem novas formas de participação do país na fase industrial do modo de produção capitalista permitindo às cidades beneficiárias aumentar seu comando sobre o espaço regional. Isso acarretou no rompimento da regência do tempo "natural", que cedeu lugar a um tempo lento nas circulações internas do território, associadas com um tempo rápido para as relações com o exterior. Ou seja, a integração àquela época não prescindiu dos mais novos desenvolvimentos técnicos, como a telegrafia e o avião, por isso falar-se numa mecanização do território.

Tem-se que a partir do século $X X$, a história do território brasileiro é profundamente marcada pelas políticas nacionais de integração nacional através de redes físicas de transportes. Estes programas almejavam uma unidade nacional através do fortalecimento das fronteiras, com a ambição de ocupar efetivamente vastas áreas pouco habitadas do Brasil, principalmente nas regiões Sul, Centro-Oeste e Amazônica.

Costa (1999) lembra que Camille Vallaux já demonstrava que a estrutura geral da circulação de um país (interna) e aquilo que ela projeta em termos de fluxos (externa) apresenta ao longo da história um significado triplo: primeiro, como reveladora da estratégia nacional de coesão interna e defesa da integridade territorial; segundo, revelando a natureza da projeção externa de um Estado; e em terceiro, como infraestrutura econômica ou meios de transporte de pessoas, bens e informações. 
Conforme Pardo (1957, p. 312) a aviação seria o instrumento ideal para se vencer a tirania da distância, permitindo assim a incorporação geoeconômica da Amazônia à vida continental. Além disso, a aviação atuaria como um fator de colonização do interior do território e consolidaria a unificação política do Estado brasileiro.

De Martonne (1948) acreditava que as possibilidades dadas pela circulação aérea abririam um novo capítulo da geografia econômica mundial sendo que ao mesmo tempo deixaria entrever, graças às facilidades sempre maiores de trocas de produtos e ideias, uma melhoria nas condições de vida e um porvir com menos incertezas.

Sobre o transporte aéreo em países desenvolvidos de vasta superfície, Spill (1973) defende que a aviação pode representar um papel complementar aos transportes terrestres e participar da elaboração da organização espacial; já nos países subdesenvolvidos e naqueles onde as barreiras geomorfológicas podem impedir a construção de infraestruturas terrestres lineares (ferrovias e rodovias), ele pode suprir as carências e ajudar na estruturação do espaço.

Considerando-se que o sistema de transporte aéreo é um dos agentes responsáveis pela atual configuração do território brasileiro, apontamos uma periodização em três momentos a partir desse sistema de transporte. O primeiro período tem início no começo da década de 1910, mais precisamente em 1913 (com a criação da Escola Brasileira de Aviação, no Rio de Janeiro, e da Escola de Aviação da Força Pública, em São Paulo - primeiros "cursos" de pilotagem do país) e se estende até o início da década de 1950. Durante esse período as políticas estatais buscavam promover uma integração geopolítica do território nacional através da consolidação de suas fronteiras nacionais. Nesse período, concomitante ao surgimento de linhas aéreas interiores no Brasil, começa a se intensificar a exploração por empresas privadas das linhas aéreas litorâneas. Todavia, mesmo com essa intensificação, o sistema de transporte aéreo no território brasileiro ainda mantinha um enfoque geopolítico mais acentuado, sendo que a busca por essa integração geopolítica é o elemento que caracteriza tal período.

Nesse contexto, a aviação promovia a ligação pontual entre parcelas territoriais que, até então, encontravam-se isoladas, através do papel desempenhado pelos Correios Aéreos Militares, que depois se transformaram em Correio Aéreo Nacional.

A partir do final da Segunda Guerra Mundial e início da década de 1950 essas políticas estatais também passariam a visar a promoção de uma integração geoeconômica do território (em que foram determinantes os planos desenvolvimentistas da época, principalmente com o início da construção de Brasília e a malha rodoviária nacional), tendo em vista que as bases da integração geopolítica já haviam sido lançadas. Santos (1979), discutindo os "começos da integração" no Brasil, lembra que entre 1945 e 1950 a indústria brasileira ganha novo ímpeto e a cidade de São Paulo se afirma como metrópole fabril do país, pois ocorre uma mudança estrutural no esquema produtivo associado a uma maior seletividade geográfica da produção industrial, mediante uma polarização que é mais clara e mais 
forte. Segundo o autor, uma nova noção de ordem e de progresso fora imposta pela mão do Estado, entretanto com o auxílio do grande capital.

Esse novo enfoque, com grande peso geoeconômico, que se dá no pós-guerra, marca o advento de nosso segundo período. Somados à construção de Brasília e ao início da implantação de uma malha rodoviária nacional, os programas de incentivo à colonização do interior do país, sobretudo da região Centro-Oeste, reforçaram o avanço de frentes pioneiras agropecuárias oriundas da região Sul e Sudeste, que passaram a ter o apoio de programas estatais específicos, através de investimentos em infraestrutura de transporte, de pesquisa de novas variedades e métodos de cultivo e do financiamento da produção agrícola e pecuária. Nesse período, com as linhas aéreas litorâneas já consolidadas e exploradas por empresas privadas, a aviação no interior do território nacional apoiou os programas de colonização e ocupação da região, como por exemplo, o programa de colonização da Fundação Brasil Central (FBC), que antes de formar novas estradas no Centro-Oeste usava a aviação para adentrar onde, ainda, não havia cidades e malha urbana. No segundo período, o sistema de transporte aéreo auxiliou e ao mesmo tempo promoveu a inserção de novas parcelas territoriais à lógica do mercado interno, que vinha buscando se solidificar. Esse momento da aviação na formação territorial do Brasil se estende até o final da década de 1970 e início dos anos 1980, com o advento do meio técnico-científico e informacional (Santos, 1996a), dando início ao terceiro período que perdura até nossos dias.
Nesse terceiro período a implantação de modernas tecnologias de comunicação permitiu que a produção propriamente dita (tanto a industrial quanto a agrícola modernizada) se dissociasse de seu comando, que cada vez mais foi se concentrando em um ponto do território brasileiro, notadamente na capital paulista.

A aviação passa a desempenhar um papel novo, respondendo pela aproximação daquilo que cada vez mais vai se "separando" (produção e comando). Santos (1979) afirma que entre os períodos da integração interior do território, e deste ao mercado mundial, houve um longo período para que se chegasse a uma "integração desarticulada" que só poderia ser atingida se se impuserem paralela e completamente, de um lado, a mundialização da economia, e de outro, a integração interna do país (por meio dos transportes, das comunicações, do mercado e da presença do Estado).

\section{As estratégias de integração geoeconômica $e$ as frentes pioneiras na região Centro-Oeste do Brasil}

A integração territorial no século $X X$ fez com que a atenção do Estado Brasileiro se voltasse para as regiões Centro-Oeste e Norte com a proposta de Getúlio Vargas da "Marcha para Oeste", uma diretriz que se converteu no imperativo dos programas de segurança e soberania nacional que visavam ocupar aquilo que fora denominado de "vazio demográfico" pelos geopolíticos brasileiros.

Todavia, é justo manifestar que os projetos nacionais de integração sempre estiveram atrelados às elites políticas que, muitas vezes também eram as elites 
econômicas à essa época; com isso, a busca de integração territorial de nosso país representou, na verdade, estratégias de sobrevivência dessas elites políticas.

Nesse molde se enquadra o discurso da proposta getulista de avançar ao interior do Brasil. Tal proposta, entretanto, é criticada por Lenharo (1986, p. 14) quando afirma que:

[...] em um momento em que eram negadas as vias institucionais de participação política, o regime [getulista] promovia as suas formas de participação; toda a estratégia de propaganda armada sob o slogan Marcha para Oeste visava, entre outros alvos, criar um clima de emoção nacional de modo a que todos os brasileiros se vissem marchando juntos, e, conduzidos por um único chefe, consumassem coletivamente a conquista, sentindose diretamente responsáveis por ela.

Moraes (2002) recorda que a incorporação material de novas terras foi acompanhada pela violência que marca o avanço da frente pioneira, ao mesmo tempo em que essa apropriação simbólica significava uma nova epopeia na construção do país. Durante o governo de Getúlio Vargas a Marcha para Oeste induzia a ideia de uma segunda conquista do território, animando assim uma nova onda expansionista impulsionada pelo ideal de modernização.

Tal programa político tem início em junho de 1943 com a Expedição Roncador-Xingu que, partindo de Uberlândia/MG tinha o objetivo de atingir Manaus abrindo caminhos para posterior ocupação; ainda em setembro de 1943 a Roncador-Xingu foi declarada de interesse militar e foi incorporada dois meses depois à recémcriada Fundação Brasil Central, a "menina os olhos" da política getulista de integração nacional. A Fundação Brasil Central foi um órgão subordinado diretamente à Presidência da República e tinha como objetivos principais o "desbravamento" e promover a "colonização" das regiões Centro-Oeste e Norte do Brasil.

Tal empreitada era realizada ao custo do trabalho de diversos peões que abriam as picadas a facão. "Em cada nova etapa vencida, ao longo da picada, instalaram-se postos de contato e abastecimento, cultivaram roças, construíram campos de pouso e fizeram levantamentos topográficos, estabelecendo a locação de futuras rodovias" (FBC, 1961, p. 9). Para ter êxito a campanha recebeu 0 amparo do Ministério da Aeronáutica no início, velando pela segurança dos expedicionários, socorrendo-os ao longo da sua rota, e depois, cedendo aviões para os trabalhos de reconhecimento, fornecendoIhes combustíveis, manutenção e pilotos. "Criando novas linhas do Correio Aéreo Nacional nas regiões desbravadas, a Aeronáutica tem prestado uma ajuda decisiva ao Brasil Central" (idem, p. 14).

Na empreitada da Marcha para o Oeste, sem o auxílio da aviação, seria praticamente impossível o avanço das trilhas e picadas pelo cerrado brasileiro. Ao tratar da Expedição Roncador-Xingu, Villas Bôas e Villas Bôas (1994) lembram que antes deles partirem para novas regiões, faziam sobrevoos analisando o relevo, a vegetação, possíveis lugares para acampamentos e se havia a presença de tribos indígenas. Com isso, traçavam os melhores caminhos para a abertura das picadas, que depois se tornariam trilhas e em seguidas se transformariam em estradas. 
Após o período de governo de Getúlio Vargas, as manobras políticas do Estado foram carregadas de atributos ideológicos visando fundamentar a estratégia estatal e, ao mesmo tempo, torná-las aceitáveis, partindo-se do discurso da "modernização" e da "ocupação" do território que, ao final, promoveriam 0 tão almejado desenvolvimento (econômico e social) do país. O incentivo à migração, viabilizado posteriormente através das cooperativas de colonização, possibilitou o florescimento das primeiras agrovilas no Centro-Oeste, ainda que sua população não tivesse praticamente nenhuma infraestrutura básica.

$$
\text { No processo inicial de ocupação, }
$$
concomitante à construção dessas primeiras agrovilas, a aviação ainda desempenhou importante tarefa (Figura 1).

Figura 1 - Transporte de animais de raça para as regiões centrais do Brasil

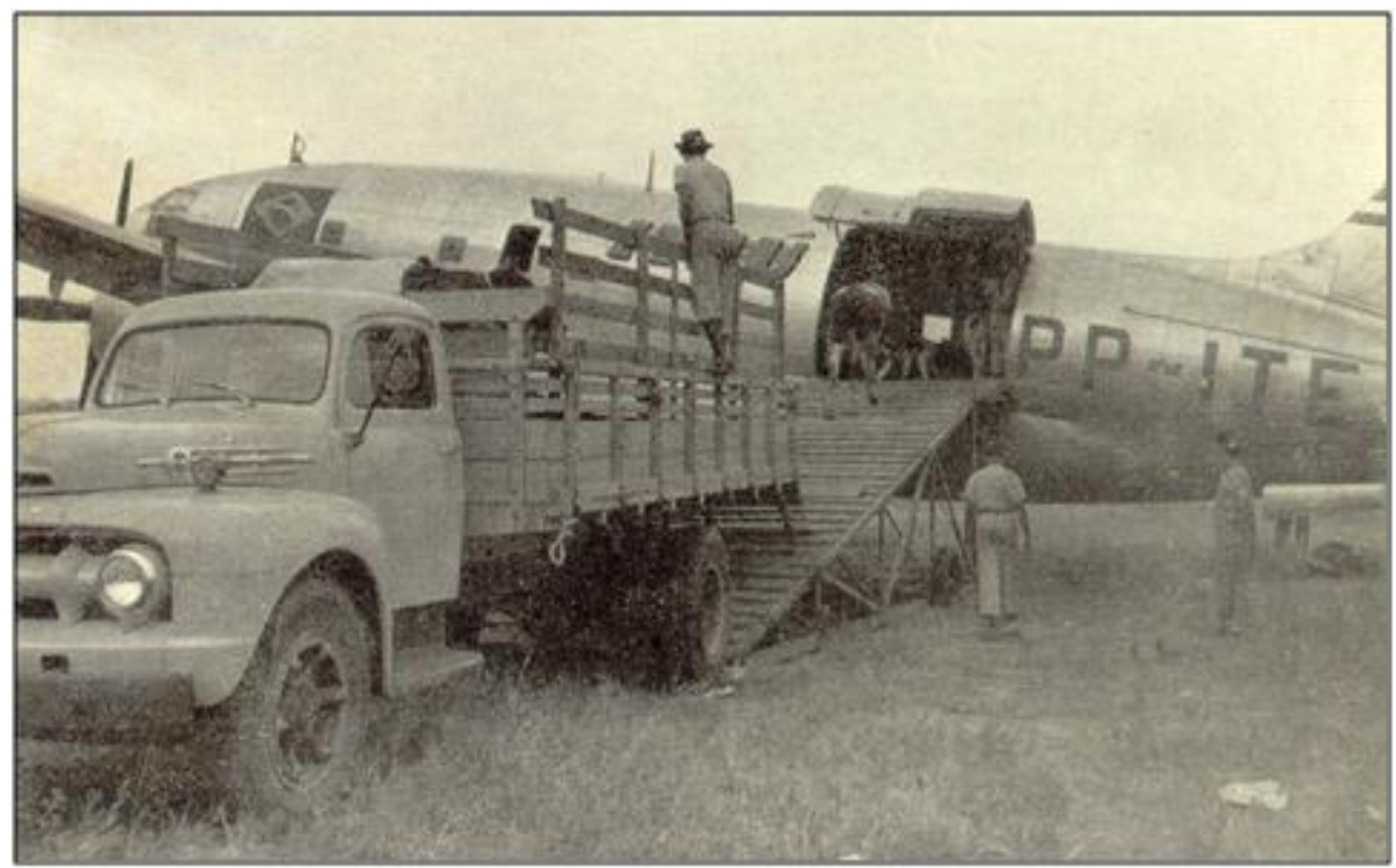

Fonte: Pépin (1956).

A Figura 1 mostra o transporte de animais do Rio de Janeiro para os estados do Centro-Oeste realizado através de aviões, dada a precariedade ou mesmo inexistência de estradas que chegassem às regiões mais remotas. Já a Figura 2 apresenta a relevância da aviação ao viabilizar a chegada das primeiras famílias de colonos, oriundos principalmente dos estados do sul do Brasil. 
Figura 2 - Primeiras famílias de colonos em Canarana (MT)

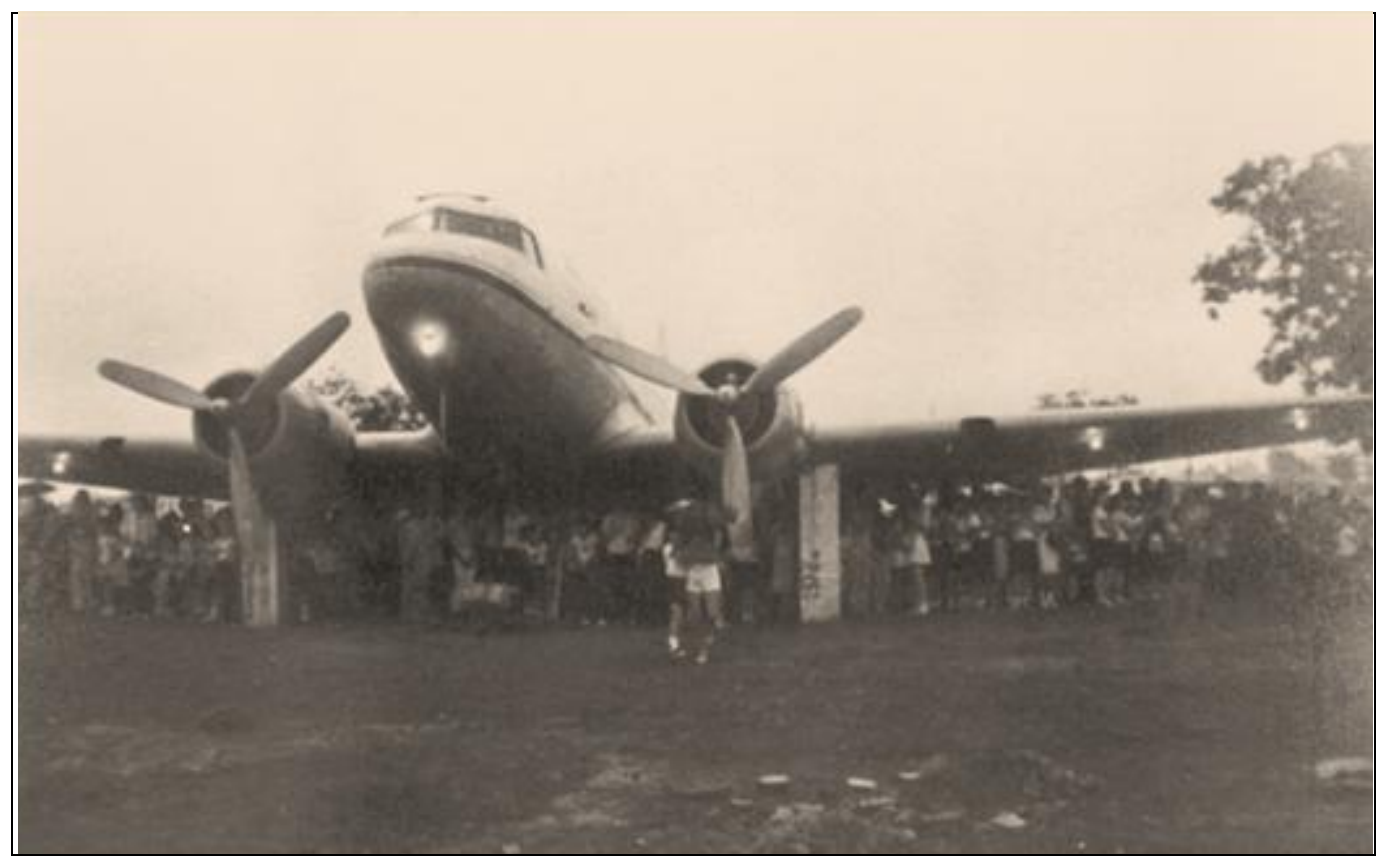

Fonte: Acervo do Prof. Dr. Hidelberto de Sousa Ribeiro - UFMT (s/d).

A Figura 2 ilustra um momento do município de Canarana/MT. A história desse município vincula-se diretamente ao uso da aviação no transporte de colonos, oriundos principalmente do interior do Rio Grande do Sul, para o interior de Mato Grosso. A Coopercana (Cooperativa Agropecuária Mista Canarana Ltda.) foi a responsável pelo transporte de cerca de 300 famílias gaúchas no início da década de 1970 em seu avião modelo DC3.

Para Cataia (2001, p. 131) com a implantação de rodovias e a expansão das frentes agrícolas em direção ao Centro-Oeste e Norte do Brasil, preparou-se as bases para a integração horizontal do território, ou seja, pôr fim ao "arquipélago" e ligar (por rodovias, ferrovias, aeroportos e telecomunicações) os vários lugares do território brasileiro, mas ao mesmo tempo estavam sendo implantados novos sistemas técnicos, promovendo uma verdadeira integração vertical do território.
A promoção da fluidez corporativa e o sistema de transporte aéreo como uma das bases da modernização agrícola da região Centro-Oeste

As possibilidades técnicas do atual período fazem com que o trabalho possa ser repartido entre os lugares, levando a uma refuncionalização das áreas portadoras de densidades pretéritas e à ocupação de áreas até então rarefeitas, como ensinam Santos e Silveira (2001). A incorporação do CentroOeste ao processo produtivo nacional se deu sob a égide do que Santos (2001) chamou "agricultura científica globalizada" e a expansão da fronteira agrícola pelos estados do Centro-Oeste tem no desenvolvimento dos sistemas de transporte rodoviário e aeroviário vetores fundamentais de expansão.

O desenvolvimento da aviação é fator de destaque no pioneirismo da expansão agrícola da cultura de soja, pois através das ligações ponto a ponto se chega cada vez "mais à frente", mais ao noroeste do Brasil, 
reclamando a necessidade da implantação de modernizações nas vias de escoamento, ou seja, no Centro-Oeste a soja chegou concomitante com a modernização para o escoamento da produção. Todavia, dada a precariedade dos sistemas de transportes terrestres no Centro-Oeste o sistema de transporte aéreo cumpre o papel eficaz de transportar os "decididores" do agronegócio. Waniez (1992) em seu trabalho sobre a região dos cerrados brasileiros lembra que em seus dois milhões de quilômetros quadrados, o avião é o meio de transporte privilegiado da classe dirigente brasileira e que os táxis-aéreos são onipresentes. Contudo, são reservados aos grandes proprietários de terras, políticos e executivos de grandes empresas nacionais e multinacionais.

$\mathrm{Na}$ economia do agronegócio é exigido um envolvimento muito maior por parte dos sojicultores no período atual, sobretudo quando as cotações de preço, assim com a lógica produtiva, muitas vezes, são decididas em outras localidades, isso os torna muito mais do que simples agricultores, isto os torna responsáveis e promotores das mudanças territoriais ocasionadas por essa racionalidade econômica que, para se efetivar, tem no uso de sistemas de transportes mais velozes e eficientes (especialmente o sistema de transporte aéreo flexível), a possibilidade de controlar a produção à distância. Na escala regional muitos produtores optam por residir em cidades com maior infraestrutura de serviços, assim como muitos deles possuem fazendas em mais de uma localidade, fato que demanda deslocamentos para o acompanhamento do processo produtivo.
Soma-se a isso na escala nacional, a dissociação entre produção e comando (com a efetivação deste último na cidade de São Paulo) que tem no uso do sistema de transporte aéreo flexível uma ferramenta da gestão corporativa. Nesse contexto, essa hierarquização do sistema urbano brasileiro, que apresenta a capital paulista como referência no controle e comando das atividades produtivas espalhadas pelo país, tem nos sistemas de transporte do território, os vetores que permitem o deslocamento corporativo no país. Santos (1994) aponta que atividades modernas presentes em diversos pontos do país apoiam-se em São Paulo para um número crescente de tarefas essenciais. A capital paulista fica presente em todo o território brasileiro graças a esses novos nexos geradores de fluxos de informação indispensáveis ao trabalho produtivo esse papel é devido às suas atividades quaternárias de criação e controle, tendo em vista que atualmente são os fluxos de informação que hierarquizam o sistema urbano.

Silva (2001) comenta que São Paulo é uma metrópole onipresente porque seu tempo atinge os mais diversos lugares, e que este é um tempo corporativo que se sustenta pela produtividade e pela competitividade e, por conseguinte, racionalizado milimetricamente, transformando os demais tempos em temporalidades subalternas já que as formas do acontecer hierárquico acentuam a seletividade dos investimentos e a maximização dos lucros a partir do momento que a capital paulista torna-se o principal polo produtor de informações e onde se instalam as firmas de consultorias, que classifica como firmas produtoras de informação, responsáveis pelo alargamento dos contextos da globalização. 
A metrópole paulista se afirma concentrando as sedes do capital industrial e financeiro e, ainda, de uma série de atividades relacionadas ao terciário superior que são fundamentais para a direção do processo de reprodução do capital em geral, além disso, nela se concentra a atividade intelectual que a torna um lugar privilegiado ao que se refere ao trabalho de concepção, inovação e criação (LENCIONI, 2003).

Apesar da desconcentração da produção que ocorreu no território nacional, a grande corporação não pode prescindir da capital paulista, pois é nela que se localizam os serviços altamente especializados, aqueles que tornam possível a fluidez da economia nacional. O comando da produção acontece tanto pela própria empresa, quanto por outros agentes do círculo de cooperação: serviços especializados, consultorias, bolsas de investimentos, entre outros, e que o sistema de transporte aéreo flexível promove os contatos face a face que são necessários aos negócios da economia global colocando em contato os lugares da produção propriamente dita com o lugar do seu comando.
Cordeiro e Ladeira (1994) lembram que o impacto das novas tecnologias de informação no período atual poderia manter a tecnocracia dirigente controlando as ações nas sedes das corporações ou empresas, mas não se pode desconsiderar a necessidade constante de contatos pessoais, face a face, intra e inter-relacionais. Scott et al. (2001, p.15) afirmam que a presença física dos dirigentes e empresários se faz necessária nas grandes metrópoles, pois se eleva a probabilidade de encontros e reuniões nos quais conhecimentos economicamente úteis ao que tange ao comando corporativo são produzidos.

O sistema de transporte aéreo flexível, que liga pontualmente São Paulo às áreas de produção do território brasileiro indica sua importância ao coexistir com o sistema de transporte aéreo rígido. Verificase (Tabela 1) que no ano de 2004 o sistema de transporte aéreo flexível se faz presente mesmo com a existência do sistema de transporte aéreo rígido.

Tabela 1 - Número de ligações aéreas (pousos e decolagens) entre a cidade de São Paulo (Congonhas, Guarulhos ou Campo de Marte) e as capitais do Centro-Oeste ${ }^{2}$

\begin{tabular}{ccccccc}
\hline \multirow{2}{*}{ Ano } & \multicolumn{2}{c}{ Goiânia - Go } & \multicolumn{2}{c}{ Campo Grande - MS } & \multicolumn{2}{c}{ Cuiabá - MT } \\
\cline { 2 - 8 } & $\begin{array}{c}\text { transporte } \\
\text { aéreo rígido }\end{array}$ & $\begin{array}{c}\text { transporte } \\
\text { aéreo flexível }\end{array}$ & $\begin{array}{c}\text { transporte } \\
\text { aéreo rígido }\end{array}$ & $\begin{array}{c}\text { transporte } \\
\text { aéreo flexível }\end{array}$ & $\begin{array}{c}\text { transporte } \\
\text { aéreo rígido }\end{array}$ & $\begin{array}{c}\text { transporte } \\
\text { aéreo flexível }\end{array}$ \\
\hline 2000 & $--*$ & -- & 3.211 & 381 & 1.751 & 274 \\
\hline 2002 & -- & -- & 5.811 & 341 & 373 & 302 \\
\hline 2004 & 6.771 & 645 & 4.691 & 493 & 778 & 309 \\
\hline
\end{tabular}

\footnotetext{
${ }^{2}$ Os dados primários apresentados na Tabela 1 foram capturados e fornecidos pelo DAC - Departamento de Aviação Civil (órgão militar). Com a mudança de DAC para Anac - Agência Nacional de Aviação Civil (órgão civil), em setembro de 2005, os dados deixaram de ser fornecidos e tabulados e não foi possível a manutenção e atualização contínua da série histórica.
} 
Nos aeroportos de Goiânia/GO, Campo Grande/MS e Cuiabá/MT a porcentagem das ligações aéreas do sistema de transporte aéreo flexível é, respectivamente $8,6 \%, 9,5 \%$ e $28,4 \%$ em relação ao total de ligações apresentadas nesses estados, ou seja, porcentagens altamente relevantes partindo do pressuposto de que a possibilidade de acesso a esses aeroportos é dada, haja vista a presença do sistema de transporte aéreo rígido. Reitera- se então essa importância da coexistência do sistema de transporte aéreo flexível.

A importância da metrópole paulista também se percebe no comando da produção de soja do território brasileiro. As sedes das grandes empresas exportadoras do grão estão, em sua maioria, localizadas na Região Concentrada, sobretudo na capital de São Paulo, enquanto as áreas produtoras se localizam em outras parcelas do território nacional (Mapa 1 ).

Mapa 1 - Brasil 2004 - Hectares plantados de soja no ano de 2004, por municípios e número e localização das sedes das empresas que exportaram mais de US\$ 50 milhões (FOB) no biênio 2003/2004*

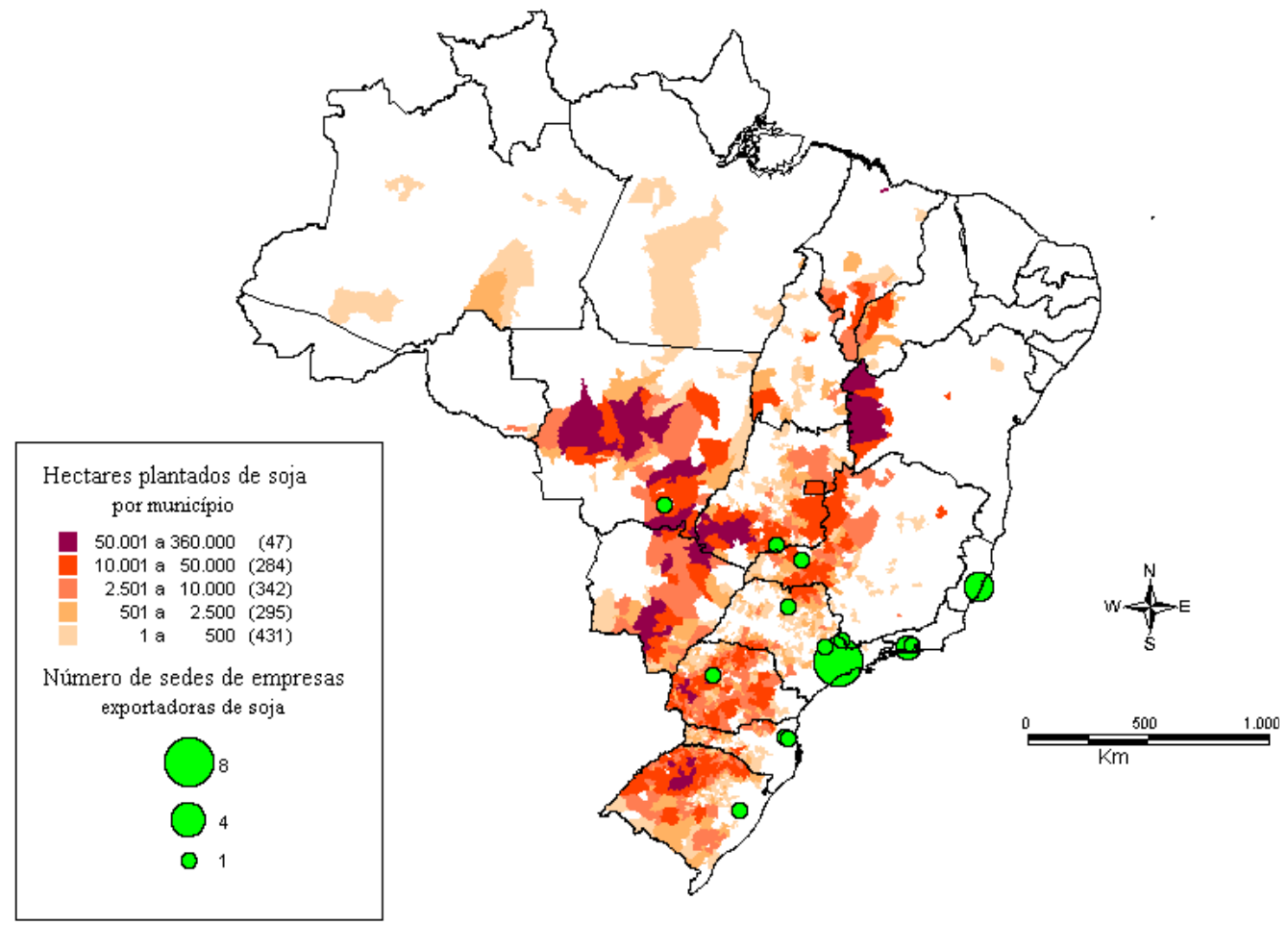

Fonte: Gallo (2006).

Nos dizeres de Cordeiro e Ladeira (1993, p. 38) o transporte aéreo é o elemento que permite a realização da complementaridade entre as parcelas especializadas do espaço interno. Além disso, vão dizer que "dada a especialização territorial, maior é a divisão do trabalho e a exigência de circulação".
O fluxo aéreo de pequenas aeronaves viabiliza essa fluidez, já que este tipo de deslocamento, presente nas negociações econômicas, permite a circulação da elite dirigente e também a comunicação da informação corporativa, já que é essa elite que possui as informações desencadeadoras de processos produtivos e que (muitas vezes) 
por serem altamente sigilosas e confidencias não podem circular pelas redes tradicionais de telecomunicações.

A circulação de aviões dá eficácia à comunicação de informações estratégicas, mas é o movimento dessa informação que vai comandar a mobilidade dos homens e das mercadorias, da produção, ou seja, o motor neste caso é informacional. "A informação é o vetor fundamental do processo social e os territórios são, desse modo, equipados para facilitar a circulação" (SANTOS, 2002, p. 239).

A seletividade no uso do território brasileiro promovida por e para alguns agentes da economia, tem na informação um elemento fundamental para a maior eficiência da fluidez material, mas também imaterial.

A questão da fluidez do espaço apresenta-se agora em outros termos. Como a informação e as finanças passam a ser dados importantes, se não fundamentais, na arquitetura da vida social, o espaço total de um país, isto é, seu território enquanto suporte da produção em todas as suas instâncias, equivale ao mercado. Desse ponto de vista distinguem-se, no país, áreas onde a informação e as finanças têm maior ou menor influência, da mesma maneira que antes a questão se colocava quanto aos produtos e à mão de obra. Embora as estatísticas por elas mesmas não o digam, definem-se agora densidades diferentes, novos usos e uma nova escassez (SANTOS; SILVEIRA, 2001, p. 53).

A informação não somente informa e comunica, no período atual ela estrutura o quadro socioespacial e neste sentido ela ganha o atributo de ser um recurso estratégico para os sistemas produtivos contemporâneos das corporações globais pra que estas possam recriar permanentemente um cenário mundial de competitividade, "o conteúdo e a trama dos fluxos de informação são pois, reveladores dos modos como a inteligência da globalização circula nos territórios nacionais, levando uma ordem vertical, organizacional aos lugares" (SILVA, 2001, p. 104). Esta autora ainda alerta que a informação pode ser qualificada como um híbrido pois pode ser, de um lado, suporte material, como meio, e de outro, como mercadoria, como forma de ação.

\section{Considerações finais}

No Brasil existem desigualdades regionais profundas, não se pode dizer que 0 meio técnico-científico e informacional (SANTOS, 2002) é difundido por todo o território nacional; o que se tem são manchas espalhadas pelo território, que tornam a cidade de São Paulo (centro da Região Concentrada) o lugar com o maior grau de modernidades e densidade informacional.

Por meio dos sistemas de transporte, especialmente do sistema de transporte aéreo (através de sua ação pontual, que tende a regular a produção de commodities agrícolas voltadas à exportação), observa-se a promoção de uma fluidez no território brasileiro que interliga pontos dessa economia dinâmica que, na maioria das vezes têm suas atenções voltadas para a lógica econômica global, deixando à mercê do ocaso as partes excluídas causando, não raro, tensões inter-regionais.

Ao se propor um estudo dos fluxos aéreos no país, não buscamos apenas descrever o processo de funcionamento da aviação, buscamos também, apontar como o 
sistema de transporte aéreo contribui para integrar o país ao mesmo tempo em que seu uso é altamente seletivo. Num país onde há desigualdades latentes, ter um elevado número de aeronaves particulares evidencia, de mais uma maneira, a grande concentração de renda que o país apresenta. Além disso, o Estado, ao dotar o território de infraestruturas (rodovias, ferrovias, aeroportos etc.), muitas vezes reduz seus

é tornado cada vez mais flexível, na medida em que passa a ser o agente promotor e viabilizador das modernizações e investimentos na esfera social para atender aos imperativos das grandes corporações.

A importante atuação do Estado, preparando o território para determinados usos indicaria que o mesmo Estado que se enfraquece é aquele que assume novas funções, principalmente como agente regulador das atividades, afinal quem faz as regras também é agente do jogo. O que se percebe é um fortalecimento do Estado, que infraestruturas territoriais que servem aos complexos corporativos globais, que se instalam nos territórios nacionais.

\section{Referências bibliográficas}

\section{CATAIA, M. Território nacional e} fronteiras internas: a fragmentação do território brasileiro. Tese (Doutorado em Geografia Humana) Departamento de Geografia, Faculdade de Filosofia, Letras e Ciências Humanas, Universidade de São Paulo, São Paulo, 2001.

; GALLO, F. Sistema de transporte aéreo flexível e integração território brasileiro. Geonordeste (UFS), v. 2, p. $9-30,2007$.

CORDEIRO, H. K.; LADEIRA, F. S. Buarque. O espaço aéreo favorece a desterritorialidade? In SANTOS, Milton; SOUZA, M. A,; SILVEIRA, M. L. Território: globalização e fragmentação. São Paulo: Hucitec/Anpur, 1994.

. Os dois circuitos de fluxos do sistema aéreo no Brasil atual. In: 30 SIMPÓSIO DE NACIONAL DE GEOGRAFIA URBANA, Rio de Janeiro, 1993. Anais..., Rio de Janeiro: AGB, 1993.

COSTA, W. M. Políticas territoriais brasileiras no contexto da integração sulamericana. Território, Rio de Janeiro: UFRJ/Laget, ano IV, n. 7, jul./dez. 1999.

DE MARTONNE, E. Géographie aérienne. Paris: Albin Michel, 1948.
FBC. FUNDAÇÃO BRASIL CENTRAL. Relatório de Atividades. [S.I.; s.n.], 1961.

GALLO, F. O papel do transporte aéreo na integração do território brasileiro. 2006. Dissertação (Mestrado em Geografia) - Instituto de Geociências, Universidade Estadual de Campinas, Campinas, 2006.

LENCIONI, S. Cisão territorial da indústria e integração regional no Estado de São Paulo. In: GONÇALVES, M. F. et al. (Orgs.). Regiões e cidades, cidades nas regiões: o desafio urbano-regional. São Paulo: Unesp/Anpur, 2003.

LENHARO, A. Colonização e trabalho no Brasil: Amazônia, Nordeste e Centro-Oeste - os anos 30. 2. ed. Campinas: Unicamp, 1986.

MORAES, A. C. R. Território e história no Brasil. São Paulo: Hucitec/Annablume, 2002.

PARDO, A. M. Brasil: la gran potencia del siglo XXI. 2. ed. Santiago de Compostela: Porto y Cia., 1957.

PÉPIN, E. Géographie de la circulation aérienne. 4ème ed. Paris: Gallimard, 1956. 
SANTOS, M. O retorno do território. In: SANTOS, Milton. Da totalidade ao lugar. São Paulo: Edusp, 2005. (Coleção Milton Santos, 7.)

. Por uma outra globalização. 6 . ed. São Paulo: Record, 2001.

. O território e o saber local: algumas categorias de análise. Cadernos IPPUR, ano XII, n.2, Rio de Janeiro: UFRJ, 1999, p. 15-25.

Metamorfoses do espaço habitado. 5. ed. São Paulo: Hucitec, 1997.

\section{Por uma economia política da}

cidade. São Paulo: Hucitec, 1994.

. Do espaço sem nação ao espaço transcionalizado. In: RATTNER, $\mathrm{H}$. (Org.). Brasil 1990, caminhos alternativos do desenvolvimento. São Paulo: Brasiliense, 1979.

; SILVEIRA, M. L. O Brasil: território e sociedade no início do século XXI.

2. ed. Rio de Janeiro: Record, 2001.

SCOTT, A. et al. Cidades-regiões globais. Espaços \& Debates, revista de estudos regionais e urbanos. São Paulo: Anpur, ano XVII, n. 41, 2001.
SILVA, A. M. B. A contemporaneidade de São Paulo: produção de informações e novo uso do território brasileiro. Tese (Doutorado em Geografia Humana) - Departamento de Geografia, Faculdade de Filosofia, Letras e Ciências Humana, Universidade de São Paulo, São Paulo, 2001.

SILVEIRA, M. L. Ao território usado a palavra: pensando princípios de solidariedade socioespacial. In: VIANA, A. L. d'A.; IBAÑEZ, N.; ELIAS, P. E. M. (Orgs.). Saúde, desenvolvimento e território. São Paulo: Aderaldo \& Rotschild, 2009.

SPILL, Christiane. Le transport aérien et la région. Annales de Géographie. Bulletin de la Société de Géographie. Paris: Armand Colin, mai/juin 1973, LXXXII année.

VILLAS BÔAS, C.; VILLAS BÔAS, O. A marcha para o Oeste. A epopeia da Expedição Roncador-Xingu. 6. ed. São Paulo: Globo, 1994.

WANIEZ, P. Les cerrados: un espace frontière brésilien. Montpellier: G.I.P. Reclus/Orston, 1992. 